\title{
El impacto del covid-19 en Argentina y las medidas adoptadas en consecuencia
}

\section{The coviD-19 Pandemic impact in Argentina and the implemented measures}

\section{O impacto da pandemia do covid-19 na Argentina e as medidas implementadas}

AUTORES VARIOS ${ }^{*}$

* Juan Frers, contador público y abogado de la Universidad de Buenos Aires; investigador Tributario de la Universidad de Buenos Aires; miembro Grupo de Investigación Conocimientos Tributarios Latam, jf.2008@live.com / https://orcid.org/0000-0002-6001-3562. Gonzalo Aineseder, abogado de la Universidad Nacional de la Plata; asesor legal en Administración Gubernamental de Ingresos Públicos (AGIP), Argentina; miembro Grupo de Investigación Conocimientos Tributarios Latam, gonza.aineseder@hotmail.com / https://orcid.org/0000-0002-1112-0505. Hugo Alejandro Asplindh, abogado de la Universidad de Buenos Aires; asesor legal de la Administración Federal de Ingresos Públicos (AFIP), Argentina; miembro Grupo de Investigación Conocimientos Tributarios Latam, hugoale46@gmail. com / https://orcid.org/0000-0002-3785-5198. Susana Vallejos Quiroz, contadora pública y licenciada en Administración de Empresas de la Universidad Católica Argentina; fiscal y abogada de Dirección Contencioso de la Administración Federal de Ingresos Públicos (AFIP), Argentina; miembro Grupo de Investigación Conocimientos Tributarios Latam, susanavq@gmail.com/https://orcid.org/0000-00033468-9603. Romina Catena, abogada de la Universidad de Buenos Aires; asesora legal en la Secretaría de Política Tributaria del Ministerio de Economía, Argentina; miembro Grupo de Investigación Conocimientos Tributarios Latam, rominacatena@yahoo.com / https://orcid.org/00-0003-2677-2212.Alan Bitterman, máster en Derecho Penal y Ciencias Penales de la Universidad de Barcelona y Universidad Pompeu Fabra; analista legal Administración Gubernamental de Ingresos Públicos (AGIP), Argentina; miembro Grupo de Investigación Conocimientos Tributarios Latam, alan.bitterman@gmail.com / https://orcid.org/0000-0002-3022-0501. Jorge Javier Villalba, contador público de la Universidad Católica de Salta, Argentina; auditor de Procesos en Administración Federal de Ingresos Públicos (AFIP), Argentina; miembro Grupo de Investigación Conocimientos Tributarios Latam, cpjaviervillalba@ gmail. com / https://orcid.org/0000-0002-5280-4372. Luciano Almada, contador público de la Universidad Nacional de La Plata; asesor Tributario de la Dirección General de Planificación y Control de la Administración Gubernamental de Ingresos Públicos (AGIP), Argentina; miembro Grupo de Investigación Conocimientos Tributarios Latam, almadaluc@gmail.com / https://orcid.org/0000-0002-5500-9446. María de los Ángeles Jáuregui, magíster en Tributación de la Universidad de Buenos Aires; consultora en Cepal-Naciones Unidas; miembro Grupo de Investigación Conocimientos Tributarios Latam, Jaureguimariadelosangeles1@gmail.co / https://orcid.org/0000-0001-9734-5707. Matías Vallejos, licenciado en Relaciones del Trabajo de la Universidad de Buenos Aires; consultor; miembro Grupo de Investigación Conocimientos Tributarios Latam, matias_v64@ hotmail.com / https://orcid.org/0000001-7765-9231. Sandra Díaz, contadora pública de la multinational MBA - Esade Business School; especialista en impuestos y precios de transferencia de Managing Partner de @sdiaztax.net, sandra@ sdiaztax.net / https://orcid.org/0000-0002-6099-1761

DoI: https://doi.org/10.18601/16926722.n18.02 


\title{
Resumen
}

En el presente artículo se realizará un análisis de las medidas fiscales implementadas por las administraciones tributarias ante la pandemia del covid-19, partiendo del análisis de una compleja situación económico-social que se vio agravada a causa de la crisis que golpea fuertemente a la región.

Palabras clave: pandemia; covid-19; medidas tributarias; impacto económico; administraciones tributarias; economía digital.

\begin{abstract}
In this research, we will make an analysis of the tax measures which tax administrations have been taking in order to deal with the effects of the COVID-19 Pandemic. We will start studying the complex socio-economic situation which has been aggravated by the recent Pandemic and strongly affects the region.
\end{abstract}

Key words: covID-19 pandemic; tax measures; economic impact; tax administrations; digital economy.

\section{Resumo}

Nesta pesquisa, faremos uma análise das medidas tributárias adotadas pelas administrações tributárias para lidar com os efeitos da pandemia do Covid-19. Começaremos a estudar a complexa situação socioeconômica que foi agravada pela recente pandemia e afeta fortemente a região.

Palavras-chave: Pandemia covid-19; medidas tributárias; impacto econômico; administrações tributárias; economia digital. 


\section{Introducción}

Y un día nos llegó, sin preguntarnos siquiera, una pandemia. Nos miramos todos y cada uno sin alcanzar a comprender que el mundo estaba siendo atacado por un virus, el SARSCoV-2, que causa el covid-19, y cuyas consecuencias en sus habitantes resultan impredecibles. Empezaron inmediatamente las preguntas ¿cómo? ¿cuándo? ¿por qué? ¿quién? ¿quiénes? y pocas, muy pocas respuestas, salvo una, letal, contundente, paralizadora, no hay vacuna, y con ello la idea de que había que aprender a convivir con el sufrimiento y la incertidumbre de lo desconocido.

Llegaron las noticias de los infectados y muertos, primero en Asia, posteriormente en Europa y seguidamente en América, y con ello las distintas medidas de carácter excepcional adoptadas por los Estados, incluso con restricción de las libertades individuales (estado de sitio o toque de queda) en su mayor parte con el confinamiento obligatorio de sus poblaciones, ya sea de manera parcial o sectorizada por jurisdicción o total, con honradas excepciones en los llamados servicios esenciales, en especial el personal sanitario.

En ese contexto caótico y novedoso el mundo paró. Nos refugiamos en nuestras casas con planes no ya de futuro, sino de supervivencia y de llenar nuestro tiempo de forma productiva y creativa, pero, sobre todo, a pensar en el mundo en el que vivimos y en lo que hacemos (o no hacemos) por él, en las cosas más básicas quizás, aunque más importantes también como la familia y, sobre todo, en la vida. Vaya novedad, pero el mundo y nuestra rutina se apagaron, nos volvimos más caseros y simples, y ante las noticias de muertes que se multiplicaban comenzamos a observar y a pensar mirándonos retrospectivamente y a nuestro alrededor.

Esta realidad, por supuesto, no es ajena a la Argentina, por ello es necesario dar cuenta de los efectos de la pandemia en el gasto en este país suramericano, y sus efectos en su ya recesiva economía, amén del contexto laboral y la economía digital.

Y es que al observar el escenario económico de Argentina antes del covid-19, hay que decir que la situación económica presentaba equilibrios precarios. Hay que entender que con una tasa de desempleo del 10,6\% registrada durante 2019, un índice de pobreza del $35,7 \%$ durante el mismo periodo y 1,5\% correspondiente al índice de producción industrial manufacturero (IPI), sumado al índice inflacionario anual del $50 \%$ y una caída de la industria generalizada, no se puede pensar en un escenario positivo.

Además, hay que recordar que el peso argentino fue perdiendo su valor durante 2019, acumulando una depreciación del $65 \%$ desde abril de 2018, y que también, luego de una caída de 2,5\% del producto interno bruto (PIB) en 2018, la economía se contrajo un 2,5\% adicional en el primer semestre de 2019.

En síntesis, aun antes de esta crisis de característica coyuntural, este país se encontraba sumido en una fuerte recesión económica que abarcaba varios ciclos económicos seguidos, azotado por altos índices de inflación, de pobreza (sobre todo infantil), de indigencia y demás datos estructurales que denotan una fuerte desigualdad socioeconómica, con el agregado, no menor, de una robusta deuda externa contraída con organismos 
multilaterales de crédito, especialmente con el Fondo Monetario Internacional (FMI) y diversos acreedores privados. Los problemas señalados limitan el margen de maniobra que tienen los gobernantes en el impulso de políticas públicas que permitan hacer frente a la crisis. Al decir de Snowden Las epidemias son como mirarse al espejo de la humanidad, y puedo decir, no todo es bello.

\section{El presupuesto destinado para mitigar los efectos de la pandemia}

En los dos primeros meses ${ }^{1}$ de 2020 , el Gobierno destinó al gasto público (a las partidas de salud y gasto social, incluidas partidas financieras instrumentadas para los sectores más vulnerables de la sociedad) el equivalente al 4,9 del PIB. También se dieron créditos a tasa cero, destinados a monotributistas y autónomos, y las líneas crediticias a tasas preferenciales dispuestas por el Banco Nación y el Banco de Inversión y Comercio Exterior (BICE) a las empresas necesitadas de asistencia económica.

Es menester aclarar, en términos de proyecciones de la actividad económica, que la caída proyectada del PIB (prepandemia) para 2020 era de 1,6\%. Sin embargo, a raíz de la pandemia del covid-19, la caída (pospandemia) sería de 9,8\% (según fuentes privadas). Para el Banco Mundial, en cambio, la recesión sería del 7,3\%.

En el informe de la Oficina de Presupuesto del Congreso de la Nación (2020) se destacan los principales aumentos del gasto:

- Ingreso Familiar de Emergencia (IFE) de \$10.000 destinado a monotributistas categorías A y B, trabajadores, beneficiarios de la asignación universal por hijo (AUH) y personal doméstico: $\$ 89.630$ millones. Esta cifra se aplica para el mes de mayo.

- Tarjetas alimentarias, atención a comedores escolares y compra de alimentos: \$42.788 millones.

- Transferencias a las provincias: $\$ 120.000$ millones.

- El salario complementario para los trabajadores en relación de dependencia del sector privado de entre uno y dos salarios mínimos: $\$ 85.000$ millones.

- Programa de Atención Médica Integral (PAMI) \$10.000 millones.

- Equipos sanitarios y de laboratorio, productos farmacéuticos y medicinales: \$15.840 millones.

- Bono de $\$ 5000$ al personal de la salud abocado a la pandemia: \$12.066 millones.

- Aumento en el presupuesto para inversión en obra pública: \$85.926 millones.

- Créditos a tasa cero a monotributistas y autónomos: \$220.774 millones. Líneas crediticias a tasas preferenciales para garantizar la producción y el abastecimiento de alimentos, impulsar la actividad y financiar el funcionamiento de la economía: $\$ 350.000$ millones (La Nación, 24 de mayo de 2020, pp. 15 y ss.).

1 Los valores no han variado la tendencia denotada, en términos de puntos del PIB. 
También se han tomado medidas que significaron un sacrificio fiscal para el Estado al reducir su recaudación que, a la postre, significan un alivio impositivo para empresas al reducir la alícuota y la postergación del pago de las cargas patronales de su personal. Esas medidas significaron una disminución de recursos equivalente al 0,3\% del PIB.

\section{Medidas tributarias}

Con la finalidad de paliar la situación de emergencia generada por el covid-19, el Foro sobre Administración Tributaria de la Organización para la Cooperación y el Desarrollo Económicos (OCDE) elaboró un informe que recopila medidas nacionales adoptadas para ayudar a los contribuyentes afectados por la pandemia. Puntualmente, se describen respecto a esta temática las principales medidas tributarias adoptadas por los países, entre las cuales se destacan:

- La ampliación de los plazos para la presentación de declaraciones juradas y pago de impuestos; la condonación de multas e intereses; el acceso o extensión de las facilidades de pago; la suspensión del cobro.

- Reembolsos más rápidos a los contribuyentes resignando precisión y cierta rigurosidad en los controles a fin de agilizar lo más posible las solicitudes presentadas, aunque salvaguardando en todos los casos el crédito fiscal a fin de evitar dar trámite a solicitudes de reembolsos fraudulentos.

- Cambios temporales en la política de auditoría y formas de proporcionar una certeza fiscal más rápida: se implementaron cambios temporales en la política de auditoría ante la menor disponibilidad de recursos o su reasignación a otras tareas prioritarias. Entre estas medidas se destacan la modificación de los parámetros de riesgo y el empleo de mecanismos para dar certeza tributaria anticipada (tax rulings) a los contribuyentes.

- Servicios mejorados para los contribuyentes. Las administraciones tributarias están intensificando el uso de medios de comunicación digitales (mensajería directa, chat web, redes sociales, aplicaciones móviles, etc.) para reducir los contactos físicos y proporcionar respuestas más rápidas a los contribuyentes.

En este contexto, el Ejecutivo tomó medidas tributarias para auxiliar a los contribuyentes y así procurar una disminución en la pérdida casi constante de la recaudación por parte de la Administración Federal de Ingresos Públicos (AFIP).

Una de estas medidas es la creación del Programa de Asistencia de Emergencia al Trabajo y la Producción. Mediante el dictado del decreto de necesidad y urgencia DNU 376/2020 (B.O. 20/04/2020) el Poder Ejecutivo ha ampliado sustancialmente los beneficios del Programa de Asistencia (ATP) creado por el Decreto 332/2020 y su modificatorio Decreto 347/2020 ya que la dinámica del covid-19 tiene un gran impacto sobre la salud pública y la situación económico-social, lo que ha obligado a tomar medidas en periodos cortos y modificar las mismas con gran celeridad. 
En virtud de ello, los principales cambios, teniendo en cuenta la normativa vigente ordenada y actualizada, son:

- Ampliación de los beneficios a empresas cuya actividad se encuentre en el artículo 6 del Decreto 297, sus modificatorias y reglamentaciones (actividades esenciales), las cuales podrán solicitar la incorporación al programa ATP.

- Se suprimen los requisitos en cuanto a la inclusión de los trabajadores en un convenio colectivo de trabajo y a la cantidad de estos en la nómina.

- Se deroga el Programa de Recuperación Productiva (REPRO) -Asistencia Emergencia Sanitaria- y se universaliza el salario complementario abonado por el Estado nacional a los trabajadores y trabajadoras en relación de dependencia del sector privado. El mismo no podrá superar el salario del mes de febrero de 2020, con un máximo de 2 salarios mínimos vitales y móviles (SMVM) y un mínimo de 1 SMVM (a la fecha \$16.875).

- La novedad, quizás de las más relevantes, es la incorporación de los trabajadores autónomos y monotributistas, con beneficios especiales, sujetos que no se encontraban comprendidos en el programa original, los mismos podrán acceder a préstamos a tasa 0 .

- La reducción de hasta el 95\% de las contribuciones con destino al SIPA es ahora para todos los empleadores que califiquen para su obtención.

- El REPRo especial desapareció como beneficio de este programa, pero esto no obsta para que el Ministerio de Trabajo, Empleo y Seguridad Social (MTEyss) ponga en marcha el REPRO tradicional y el mismo sea de aplicación para los empleadores, según otros requisitos que no sean los específicos para el ATP.

Asimismo, entre los principales puntos de dicho programa podemos destacar:

- Asistencia a Empresas (salario complementario)

Se recomienda otorgar dicho beneficio, en forma automática, respecto de los salarios devengados en abril de 2020 a los empleadores que reúnan las siguientes condiciones:

- La plantilla de empleados de las empresas no debe superar la cantidad total de 800 trabajadoras en relación de dependencia al 29 de febrero de 2020.

- La actividad principal del empleador al 12 de marzo de 2020 se encuentre entre las definidas en las actas del Comité 1 y 2 , modificadas por la 3 .

- La variación nominal de la facturación del periodo comprendido entre el 12 de marzo y el 12 de abril de 2020 respecto al mismo periodo del año 2019 sea de 0 o inferior a 0 , es decir que el empleador no registre un incremento nominal en su facturación.

Es menester aclarar que dicho beneficio, que se otorgará en forma automática, consistirá en una suma de dinero (salario complementario) con las siguientes particularidades: 
La suma de dinero se determinará con el procedimiento establecido en el Decreto $332 / 2020$ y sus modificaciones, sobre la suma equivalente al $83 \%$ de la remuneración bruta devengada correspondiente a los potenciales beneficiarios en el mes de febrero de 2020, proveniente de las declaraciones juradas presentadas por el empleador ante la AFIP. Este beneficio lo abonará la Administración Nacional de la Seguridad Social (ANSES) en forma directa mediante acreditación en la cuenta bancaria denunciada para cada trabajador por parte de su empleador (CBU en el sistema de Simplificación Registral - Empleadores).

En aquellas empresas que cuenta con más de 800 trabajadores al 29 de febrero de 2020 , a fin de otorgarles los beneficios contemplados en el programa, se deberá evaluar su situación financiera a partir de la información recabada en el sitio web Programa de Asistencia de Emergencia para el Trabajo y la Producción - ATP de la AFIP y la restante que pudiera solicitarse a posteriori.

Además, se establecen los siguientes requisitos:

- No podrán distribuir utilidades por los periodos fiscales cerrados a partir de noviembre de 2019.

- No podrán recomprar sus acciones directa o indirectamente.

- No podrán adquirir títulos valores en pesos para su posterior e inmediata venta en moneda extranjera o su transferencia en custodia al exterior.

- No podrán realizar erogaciones de ninguna especie a sujetos relacionados directa o indirectamente con el beneficiario cuya residencia, radicación o domicilio se encuentre en una jurisdicción no cooperante o de baja o nula tributación.

- Respecto a las actividades que se transcriben en la tabla 1, además de las ayudas citadas precedentemente, se recomienda otorgar el beneficio dispuesto en el inciso b) del artículo 6 del decreto 332/2020 y sus modificatorios, que implica una reducción del $95 \%$ de las contribuciones patronales destinadas al Sistema Integrado Previsional Argentino.

Es menester sistematizar y analizar las medidas adoptadas por el Estado nacional, la Ciudad Autónoma de Buenos Aires, las Provincias de Buenos Aires, Santa Fe y Córdoba y la Comisión Arbitral del Convenio Multilateral en lo relativo al cobro de impuestos, en el marco de la pandemia covid-19. Estas persiguen la finalidad de alivianar la situación fiscal de los contribuyentes durante el aislamiento social, preventivo y obligatorio establecido por el Decreto 297/2020, sus prórrogas y normas complementarias y reglamentarias, a las que las citadas jurisdicciones adhirieron. El tema bajo estudio abarca la extensión de plazos para presentación y pago de la declaración jurada (DDJJ), planes de facilidades de pago, bonificaciones y descuentos en el ingreso de los tributos, suspensión del inicio de apremios o cobro compulsivo de gravámenes y/o de traba de embargos u otras medidas cautelares en dichos procesos, etc. Asimismo, no puede soslayarse la abrupta caída de la recaudación proyectada por el Fisco nacional y los entes locales, factor que resulta decisivo 


\section{Tabla 1.}

\begin{tabular}{|c|c|}
\hline Actividad & Descripción \\
\hline 791200 & Servicios mayoristas de agencias de viajes \\
\hline 791100 & Servicios minoristas de agencias de viajes \\
\hline 791909 & Servicios complementarios de apoyo turístico NCP \\
\hline 791901 & Servicios de turismo aventura \\
\hline 900040 & Servicios de agencias de ventas de entradas \\
\hline 939030 & Servicios de salones de baile, discotecas y similares \\
\hline 900011 & Producción de espectáculos teatrales y musicales \\
\hline 931030 & Promoción y producción de espectáculos deportivos \\
\hline 939010 & Servicios de parques de diversiones y parques temáticos \\
\hline 910200 & Servicios de museos y preservación de lugares y edificios históricos \\
\hline 900021 & Composición y representación de obras teatrales, musicales y artísticas \\
\hline 900091 & Servicios de espectáculos artísticos NCP \\
\hline 931090 & Servicios para la práctica deportiva NCP \\
\hline 931042 & Servicios prestados por profesionales y técnicos para la realización de prácticas deportivas \\
\hline 900030 & Servicios conexos a la producción de espectáculos teatrales y musicales \\
\hline 931020 & Explotación de instalaciones deportivas, excepto clubes \\
\hline 939090 & Servicios de entretenimiento NCP \\
\hline 931050 & Servicios de acondicionamiento físico \\
\hline 910300 & Servicios de jardines botánicos, zoológicos y de parques nacionales \\
\hline 939020 & Servicios de salones de juegos \\
\hline 931041 & Servicios prestados por deportistas y atletas para la realización de prácticas deportivas \\
\hline 910900 & Servicios culturales NCP \\
\hline 920009 & Servicios relacionados con juegos de azar y apuestas NCP \\
\hline 920001 & Servicios de recepción de apuestas de quiniela, lotería y similares \\
\hline 910100 & Servicios de bibliotecas y archivos \\
\hline 651310 & Obras sociales \\
\hline 651110 & Servicios de seguros de salud \\
\hline 861010 & Servicios de internación excepto instituciones relacionadas con la salud mental \\
\hline 861020 & Servicios de internación en instituciones relacionadas con la salud mental \\
\hline 862200 & Servicios odontológicos \\
\hline 862130 & $\begin{array}{l}\text { Servicios de atención médica en dispensarios, salitas, vacunatorios y otros locales de atención primaria } \\
\text { de la salud }\end{array}$ \\
\hline 862110 & Servicios de consulta médica \\
\hline 862120 & Servicios de proveedores de atención médica domiciliaria \\
\hline 863300 & Servicio médico integrado de consulta, diagnóstico y tratamiento \\
\hline 863190 & Servicios de prácticas de diagnóstico NCP \\
\hline 863120 & Servicios de prácticas de diagnóstico por imágenes \\
\hline 863200 & Servicios de tratamiento \\
\hline 863110 & Servicios de prácticas de diagnóstico en laboratorios \\
\hline 864000 & Servicios de emergencias y traslados \\
\hline 869010 & Servicios de rehabilitación física \\
\hline 869090 & Servicios relacionados con la salud humana NCP \\
\hline 870920 & Servicios de atención a mujeres con alojamiento \\
\hline
\end{tabular}




\begin{tabular}{|ll|}
\hline Actividad & \multicolumn{1}{c|}{ Descripción } \\
\hline 870910 & Servicios de atención a niños y adolescentes carenciados con alojamiento \\
\hline 870990 & Servicios sociales con alojamiento NCP \\
\hline 870220 & Servicios de atención a personas minusválidas con alojamiento \\
\hline 870210 & Servicios de atención a ancianos con alojamiento \\
\hline 870100 & Servicios de atención a personas con problemas de salud mental o de adicciones, con alojamiento \\
\hline 880000 & Servicios sociales sin alojamiento \\
\hline 949990 & Servicios de asociaciones NCP \\
\hline
\end{tabular}

Fuente: elaboración propia.

para el estudio de las medidas y los incentivos fiscales anunciados por el Gobierno nacional debido a la gran erogación que ello implica.

\section{A. Normas adoptadas por el Poder Ejecutivo Nacional y la Administración Federal de Ingresos Públicos}

A nivel nacional, la Administración Federal de Ingresos Públicos prorrogó el plazo para la exteriorización e ingreso de los tributos que fiscaliza y percibe conforme a un calendario establecido según terminación de la Clave Única de Identificación Tributaria. En la misma línea, se aplazó la presentación de declaraciones juradas de deducciones del impuesto a las ganancias $4^{\circ}$ categoría ${ }^{2}$-trabajadores en relación de dependencia-, se dispuso la suspensión de exclusiones y bajas de oficio del régimen simplificado para pequeños contribuyentes (Monotributo) ${ }^{3}$, así como también del impuesto al valor agregado (IVA), la extensión del término de presentación y pago. Asimismo, se dispuso una nueva prórroga para la presentación y el pago del impuesto a las ganancias, los bienes personales y el impuesto cedular a la renta financiera para la persona humana y sucesiones indivisas ${ }^{4}$.

En relación con el impuesto sobre los bienes personales, se dispuso una prórroga para la aplicación de alícuotas diferenciales en la repatriación de bienes hasta el 30 de abril de 2020, cuando el plazo original era el 31 de marzo de 2020, incorporándose nuevos vehículos de inversión para lograr mayor flexibilidad en la norma. Por otra parte, se dispuso el aplazamiento al 06 de mayo de 2020 para el ingreso del pago a cuenta de este tributo para quienes hayan decidido no repatriar el $5 \%$.

Respecto de las micro, pequeñas y medianas empresas inscritas en el programa Mipyme, suspendió la traba de embargos y otras medidas cautelares hasta el 30 de junio de $2020^{6}$. En sintonía con estas medidas, se determinó la prórroga de términos para el

3 RG 4687/AFIP/2020 B.O. 20/03/2020.

4 RG 4704/AFIP/2020 B.O. 18/04/2020 o B.O. 28/04/2020 y RG 4701/AFIP/2020 B.O 18/04/2020.

5 Decreto 330/2020 y RG 4691/AFIP/2020 B.O. 02/04/2020.

6 RG N4684/AFIP/2020 B.O. 20/03/2020 y RG 4705/AFIP/2020 BO 29/04/2020. 
cumplimiento de los deberes formales y materiales relativas al impuesto a las ganancias para las personas jurídicas con cierre comercial el 31 de diciembre de 2019, en el impuesto a la ganancias para los días 26 y 27 de mayo de 2020 según terminación del Código Único de Identificación Tributaria (CUIT) ${ }^{7}$. Asimismo, se otorgó un plazo especial a las personas jurídicas que actúen como agentes de retención del impuesto a las ganancias de sus dependientes para que realicen la declaración anual correspondiente al periodo fiscal $2019^{8}$.

Adicionalmente, el Organismo Recaudador dispuso la prórroga de la presentación y el pago del IVA del periodo abril de 2020 hasta los días 20,21 y 22 de mayo, según la terminación de la curT. Asimismo, las personas jurídicas contribuyentes del impuesto a las ganancias podrán acceder al Miniplan para regularizar las deudas del impuesto hasta el 30 de junio de 2020, ingresando un pago a cuenta del $25 \%$ y hasta 3 cuotas, sin tener facilidades de pago permanente las obligaciones de IVA de las MiPyME con pago diferido?. Finalmente, incrementa de tres a seis la cantidad de planes vigentes del régimen de facilidades de pago permanente para las grandes empresas. También, se estableció un régimen de facilidades de pago en el ámbito del sistema Mis Facilidades, aplicable para la cancelación de las obligaciones impositivas, aduaneras y de los recursos de la seguridad social, incluidas en los planes de facilidades de pago dispuestos por las Resoluciones Generales $4.057,4.166$ y 4.268 , sus respectivas modificatorias y complementarias, cuya caducidad haya operado hasta el día 30 de abril de 2020, inclusive, con sus respectivos intereses y multas $^{10}$.

Asimismo, debe tenerse en cuenta en Plan de Regularización Extraordinario para los contribuyentes incluidos en el programa MIPYME, cuyo plazo de acogimiento fue prorrogado por última vez hasta el 30 de junio de $2020^{11}$.

En otro orden de ideas, los contribuyentes que se hayan acogido a los beneficios del artículo 80 de la Ley de Impuesto a las Ganancias -Reorganización de Sociedades-cuentan excepcionalmente con un plazo adicional de 90 días corridos que se adicionan a los 180 días - previstos en el artículo 4 de la RG (AFIP) 2513-para comunicar a la AFIP la reorganización de sociedades, fondos de comercio, empresas o explotaciones. El citado plazo adicional es aplicable a las reorganizaciones cuyo vencimiento original de 180 días hubiera operado a partir del 20 de marzo de $2020^{12}$.

\footnotetext{
$7 \quad$ RG N4714/AFIP/2020 B.O. 13/05/2020.

8 RG 4721/AFIP/2020 y RG 4725/AFIP/2020 B.O. 28/05/2020.

9 RG 4687/AFIP/2020 B.O. 20/03/2020.

10 RG 4718/AFIP/2020 B.O. 15/05/2020.

11 Ley 27541, Solidaria Social y Reactivación Productiva y Emergencia Económica, Administrativa Tributaria y Fiscal B.O. 23/12/2019, Decretos Reglamentarios 316/2020 y RG 4690/AFIP/2020. 
En lo atinente a precios de transferencia, la presentación y pago de la Declaración Jurada se prorrogó para los periodos fiscales cerrados entre el 30 de noviembre de 2019 y el 31 de diciembre de 2019 hasta los días comprendidos entre el 18 y el 22 de mayo de $2020^{13}$.

Por otra parte, se gravó a tasa $0 \%$ la importación de insumos críticos ${ }^{14} \mathrm{y}$ dentro de los siguientes 90 días se les otorgó prioridad a las instituciones médico-asistenciales para la reducción de contribuciones patronales por su personal, así como la reducción de alícuotas en el impuesto a los créditos y débitos bancarios de dichos establecimientos ${ }^{15}$.

Finalmente, respecto a los nuevos deberes formales impuestos a los contribuyentes como, por ejemplo, la implementación y utilización de los aplicativos Presentaciones digitales ${ }^{16}$, la digitalización de datos biométricos ${ }^{17}$ y el destinado a la emisión de notas de crédito o débito $^{18}$, la primera es obligatoria hasta el 30 de junio de 2020 y las restantes se encuentran prorrogadas hasta el 30 de junio y el 1 de julio de 2020.

\section{B. Normas tributarias adoptadas por la Ciudad Autónoma de Buenos Aires frente al covid-19}

Es menester señalar que la Ciudad Autónoma de Buenos Aires y las provincias de Buenos Aires y Santa Fe fueron las que concedieron beneficios más amplios a los contribuyentes.

En primer término, la Capital Federal estableció una prórroga para la exteriorización e ingreso del anticipo $\mathrm{N}^{\circ} 3$ del año 2020 correspondiente al impuesto sobre los ingresos brutos $^{19}$, cuyo vencimiento se extendió por única vez, no habiéndose pronunciado el organismo recaudador sobre los siguientes anticipos.

Asimismo, se estableció una prórroga para la presentación y pago de Declaraciones Juradas correspondientes a los agentes de recaudación de impuesto de sellos como los escribanos y los encargados seccionales de registro dependientes del Dirección Nacional del Registro de la Propiedad Automotor ${ }^{20}$; los últimos también se vieron beneficiados por la medida dispuesta para el cumplimiento de los deberes materiales respecto del impuesto sobre las patentes de vehículos en general. También se amplió el pago del impuesto

RG 4689/AFIP/2020 B.O: 31/03/2020.

Decreto 333/2020 B.O. 02/04/2020 y RG 4696/AFIP/2020 B.O. 15/04/2020.

Decreto 300/AFIP/2020 B.O. 20/03/2020 y RG 4694/AFIP/2020 B.O. 09/4/2020.

RG 4685/AFIP/2020 B.O. 20/03/2020.

RG 4699/AFIP/2020 B.O. 17/04/2020.

RG 4688/AFIP/2020 y RG 4701/AFIP/2020 B.O. 17/04/2020.

20 Resolución 163/AGIP/2020 B.O. 08/04/2020; Resolución 164/AGIP/2020 B.O. 13/04/2020, Boletín oficial de la Ciudad de Buenos Aires (https://boletinoficial.buenosaires.gob.ar/); Resolución 173/2020 B.O 17.04/2020 y Resolución 188/AGIP/2020. 
inmobiliario, tasa retributiva de servicios de alumbrado, limpieza, mantenimiento y conservación de sumideros y sus diferencias fiscales por avalúo ${ }^{21}$.

En la misma línea, se extendió el término para la presentación y el pago de declaraciones juradas de los sujetos nominados como agentes de retención y recaudación de la contribución por publicidad y el derecho de uso urbano ${ }^{22}$. Del mismo modo, se prorrogó el plazo para el ingreso de las cuotas de los distintos de Planes de Facilidades permanentes si como los suscritos bajo las previsiones de los regímenes excepcionales de regularización tributaria creados por las Leyes 5616 y $6915^{23}$. A mayor abundamiento, se suspendieron los plazos para el ingreso del Impuesto de Sellos entre el 20 de marzo y el 21 de abril de $2020^{24}$.

Por otro lado, se prorroga hasta el día 30 de agosto de 2020 la inclusión de los contribuyentes o responsables nominados por la Resolución 2447-DGR/2019 dentro del Sistema de Verificación Continua para Grandes Contribuyentes del impuesto sobre los ingresos brutos $^{25}$.

Por otra parte, se facultó a la AGIP para establecer descuentos y bonificaciones sobre tributos empadronados que recaude sin que estos beneficios pueden exceder del $30 \%$ del producto del tributo exigido al contribuyente, y se suspendieron las trabas de embargos y otras medidas cautelares hasta el 30 de junio de $2020^{26}$.

Finalmente, se dispuso la suspensión de la traba de embargos y otras medidas cautelares hasta el 30 de junio de $2020^{27}$, con excepción de los procesos con sentencia firme cuya ejecución tuviera prescripción inminente.

\section{Normas tributarias adoptadas por la provincia de Buenos Aires}

La provincia de Buenos Aires siguió lineamientos similares a los de la Ciudad homónima, modificó el calendario fiscal fijado por el Anexo III de la Resolución normativa 4/2020, a fines de aliviar la situación económica de los contribuyentes. A través de la nueva norma extendió el plazo para el cumplimiento de obligaciones relativas al impuesto sobre los ingresos brutos, para el pago de la cuota 2 del impuesto inmobiliario urbano básico y baldío

21 Idem.

22 Resolución 192/AGIP/2020.

23 RG 4688/AFIP/2020 y RG 4701/AFIP/2020 B.O. 17/04/2020.

24 Resolución 183/AGIP/2020.

25 Resolución 194/AGIP/2020.

26 Ley 6301 B.OGCABa. 12/05/2020. Emergencia Económica y Financiera de la Ciudad, apartir de la entrada en vigencia de esta ley hasta el 31/12/2020. Decreto Reglamentario 210/2020 B.O. 15/5/2020 Idem. 
y del impuesto sobre los automotore ${ }^{28}$. Asimismo, determinó la prórroga en el vencimiento de las cuotas de todos los planes de facilidades vigentes, y estableció un mecanismo excepcional y transitorio para el alta de contribuyentes locales ${ }^{29}$. Luego, se prorrogaron todos los plazos de vencimiento de anticipos y cuotas de planes de facilidades que pudieran corresponder ${ }^{30}$.

En el mismo sentido, se procede a la revisión y reducción de distintas alícuotas contenidas en el Anexo V la Resolución normativa 02/2013 ${ }^{31}$.

Finalmente, se resolvió suspender la obligación de inscripción y actuación para los sujetos que comienzan a reunir los requisitos para ser agentes de recaudación ${ }^{32}$.

\section{Normas tributarias adoptadas por la provincia de Santa Fe}

Esta jurisdicción adoptó un temperamento parecido respecto al aislamiento social preventivo y obligatorio. De esta manera, extendió los plazos para la exteriorización -en el caso de los impuestos autodeclarativos-, y pago de los tributos provinciales. Finalmente, concedió un nuevo término para la moratoria provincial de treinta días para los vencimientos del mes de mayo, que abarca gravámenes provinciales y municipales ${ }^{33}$.

\section{E. Normas tributarias adoptadas por la provincia de Mendoza}

En la provincia de Mendoza, el fisco local optó por prorrogar la vigencia de los certificados de tasa $0 \%$, reducción de alícuotas y libre deudas en el impuesto sobre los ingresos brutos $^{34}$ y el Plan Extraordinario de Regularización de Obligaciones Tributarias hasta el 31 de mayo de $2020^{35}$, y resolvió aplazar la declaración y el ingreso de los tributos retenidos o percibidos por los agentes de recaudación de los diferentes tributos que administra y cobra $^{36}$, y prorrogó el vencimiento de la Cuota 2 de impuesto Automotor. ${ }^{37}$

28 Resolución normativa 16/2020 (ARBA) B.O.P.BA 01/04/2020; Resolución normativa 17/2020 (ARBA) B.O.P.B.A 06/04/2020; Resolución normativa 26/2020 (ARBA) B.O.P.B.A. 14/04/2020, y Resolución normativa 27/2020 B.O.P.B.A $12 / 05 / 2020$.

Resolución normativa 19/2020 (ARBA) B.O.P.B.A 08/04/2020.

Resolución normativa 24/2020 (ARBA) B.O.P.B.A 14/04/2020.

Resolución normativa 18/2020 (ARBA) B.O.P.B.A 14/04/2020.

Resolución normativa 23/2020 (ARBA) B.O.PBA 14/04/2020.

Ley Provincial 13976, Decreto 368/2020 B.O. E, S. F; Resolución 006/2020 (API); Resolución 11/2020 (API); Resolución 0026/2020 (API); Resolución 0029/2020 (API).

Resolución 16/2020 (ATM.) - B.O. 01/04/2020.

Resolución 17/2020 (ATM.) - B.O. 02/04/2020.

Resolución 24/2020 (АTM.) - B.O.M 24.04.2020.

Resolución 27/2020 (ATM) B.O.M 05/05/2020. 


\section{F. Normas tributarias adoptadas por la provincia de Córdoba}

En este caso, las medidas adoptadas fueron exceptuar del régimen de retención sobre retenciones bancarias del impuesto sobre los ingresos brutos respecto de los montos abonados por concepto de IFE y AUH ${ }^{38}$. Asimismo, se prorrogó el vencimiento de la presentación y pago del anticipo 3, lo que permitió determinar el importe por abonar sobre la base de los ingresos registrados en 2019. También se dispuso eximir del pago del impuesto de sellos a los instrumentos celebrados por el Gobierno provincial en el marco de la pandemia covid- $19^{39}$, los realizados entre instituciones financieras reguladas por la Ley 21.526 y los contribuyentes en el marco del Programa MIPyME ${ }^{40}$. Finalmente, permitió la cancelación de obligaciones tributarias provinciales con la entrega de títulos valores cuya titularidad o posesión se encuentre en cabeza de los contribuyentes o responsables de los tributos provinciales, cuando se trate de proveedores o contratistas del Estado provincial ${ }^{41}$.

\section{G. Normas dictadas por las comisiones arbitral y plenaria del convenio multilateral}

$\mathrm{Al}$ igual que los fiscos analizados hicieron con los contribuyentes radicados únicamente en su territorio, las autoridades de aplicación del Convenio Multilateral debieron estipular nuevos plazos de presentación y pago para los sujetos comprendidos en sus previsiones. En primer término, la Comisión Arbitral prorrogó la presentación de DDJJ y el pago del impuesto sobre los ingresos brutos - CM03 y CM04- para los contribuyentes con ingresos país menores a $\$ 2.500 .000$ durante el año 2019 al 30 de junio de $2020^{42}$. Finalmente, la Comisión Plenaria adoptó el mismo temperamento respecto de la Declaración Jurada anual del impuesto sobre los Ingresos Brutos -CM05-, estableciendo la utilización del coeficiente unificado conforme la Resolución 10/201943.

Finalmente, a priori podríamos concluir que la Nación y las jurisdicciones analizadas siguieron lineamientos similares conforme el Poder Ejecutivo Nacional dispuso las sucesivas prórrogas al aislamiento social preventivo y obligatorio, cada una con sus matices, tratando de lograr la reducción de la carga tributaria en pos de que a medida que las restricciones se vayan flexibilizando, llegue la reactivación económica.

38 Resolución 6/2020 (MF) - B.O.Cba 12/05/2020.

39 Decreto 271/2020 - B.O. 07/05/2020.

40 Decreto 252/2020 B.O.Cba. 22.04.2020.

41 Ley 10.691, Decreto 279/2020 30.4.2020 y Decreto 301/2020 B.O.Cba (29/4/2020).

42 Disposición de Presidencia 4/2020, B.O. 15/04/2020, ratificada por Resolución 5/2020 (C.A.) B.O. 20/04/2020.

43 Resolución Plenaria 15/2020 B:O 05/05/2020. 


\section{Teletrabajo: nuevo paradigma frente a la pandemia}

La cuarentena decretada por el Gobierno tomó por sorpresa a muchas empresas, tanto en el ámbito público como privado, que debieron recurrir al teletrabajo de manera masiva para preservar la salud de la población.

Si bien algunas firmas del rubro digital no tuvieron mayores inconvenientes en migrar hacia el home office, otras debieron tomar medidas de apuro para adecuarse a la nueva normalidad.

Asimismo, de acuerdo con un análisis de Adecco, en el área privada la pandemia trajo cuestiones inéditas para las compañías, que salieron a comprar notebooks para proveer a su personal, a contratar y capacitar líderes virtuales ya que, para los empleados, casi el $60 \%$ que realiza teletrabajo lo está haciendo por primera vez.

Como ejemplo, podemos mencionar organizaciones que se acomodan a la nueva adaptación de trabajo a nivel mundial:

- Twitter invitó a sus empleados a que trabajen desde su hogar para siempre.

- Facebook seguirá con esta modalidad hasta fin de año.

- Google y Microsoft también son una de las tantas que desarrollaron sus sistemas pensando en una cuarentena prolongada.

- Incluso, Randstad, Adecco y Manpower, las tres consultoras de empleo más importantes del mundo, se unieron para diseñar una serie de recomendaciones para el trabajo remoto.

En Argentina, el debate ya tomó estado parlamentario y al menos existen seis proyectos de ley (H. Cámara de diputados de la Nación, 2020) para reglamentarlo, y se basan en cinco puntos clave, que se abordarán a continuación.

\section{A. Igualdad de trato}

El empleador debe garantizar igualdad de trato en cuanto a remuneración, capacitación, formación y acceso a mejores oportunidades entre quienes realizan home office y quienes no.

Entre ellos deben ser incluidos los empleados de la administración pública nacional, tanto centralizada como descentralizada, en todos los niveles del Estado.

Voluntariedad: la compañía y el asalariado deberán pactar expresamente su conformidad sobre el empleo a distancia. También contemplan -con matices- la posibilidad de volver al esquema presencial.

\section{B. Privacidad y descanso}

Más allá de cuestiones puntuales, tres de las iniciativas abordan esta cuestión con expresa referencia -con algunos matices- a la preservación del derecho a la privacidad de su 
domicilio. Por ello, la asignación de las tareas deberá garantizar su derecho a contar con un descanso y un adecuado equilibrio con la carga laboral, para evitar que las personas se mantengan hiperconectadas debido a que el lugar de trabajo es igual que el de ocio. De este modo, deberán establecerse días y horarios y, de ser posible, pactar una libre distribución de la jornada con base en las necesidades del empleado, respetando siempre los límites máximos que establece la ley, es decir, 48 horas semanales.

\section{Control}

La realización de tareas a distancia requiere, por un lado, que el empleador monitoree que se están realizando las funciones; por otro, que esto no cercene los derechos a la privacidad. Las empresas, por su lado, deberán salvaguardar la intimidad, la privacidad de su domicilio y los datos personales de esta nueva modalidad de trabajo. A su vez, se encuentran los interrogantes acerca de cómo deberán establecer criterios de medición, evaluación y control sin vulnerar los derechos laborales, siempre salvaguardando la intimidad del empleado y su grupo familiar.

\section{Equipos y lugar de trabajo}

Todos los proyectos coinciden en que los medios físicos e informáticos para el teletrabajo deben ser provistos por el empleador. El colaborador es responsable de su correcto uso y conservación y de evitar que sean usados por terceros ajenos a la relación laboral. Además, deja abierta la puerta a que el empleado trabaje con sus propios dispositivos de común acuerdo, caso en el cual el empleador debe compensar la totalidad de gastos de comunicación y uso.

Las propuestas subrayan que el empleador debe brindar los medios de trabajo. Asimismo, se incorporaría la figura del trabajo a distancia móvil, que se da cuando los empleados realizan sus funciones de manera itinerante o con traslados constantes.

En síntesis, es un gran debate que se inicia en Argentina en el marco del contrato colectivo de trabajo ante este nuevo escenario que vino para quedarse ante la pandemia, que se tendrá que evaluar a nivel parlamentario, y que obligó tanto a los trabajadores como empleadores a adecuarse a esta nueva modalidad de trabajo, donde se deben garantizar derechos como trabajar en ambiente sano y seguro, conocer los riesgos asociados a su tarea y la garantía de provisión de elementos de protección personal, además de la asistencia médica.

Este escenario pone en juego muchos factores que no debemos olvidar:

- El empleador deberá proveer y mantener los equipos y asumir el costo del consumo de energía determinado según la forma de medición posible y acordada por las partes. Los servicios de internet, telefonía celular y medios electrónicos hasta ahora no formaban parte del salario. 
- Se deberá asegurar al empleado que pueda mantener una buena conectividad.

- No precarizar ni impedir con esta nueva modalidad la generación de empleos.

- Establecer las medidas que deberán tomar las Aseguradoras de Riesgos del Trabajo (ART) para asegurar que el lugar de trabajo sea seguro y libre de riesgos.

- Se deberá capacitar al personal actual en lo atinente a accesos a servidores y protocolos de seguridad para los datos y la privacidad de las personas.

\section{La economía digital y el avance implementado como consecuencia del covid-19}

Desde un punto de vista general podemos decir que Argentina, al momento de la llegada de la pandemia, se encontraba en una etapa de incorporación paulatina y de todavía bastante experimentación en relación con la economía digital. A continuación, se analiza el escenario según la normatividad expedida a marzo de 2020.

\section{A. Servicios digitales en IVA}

La más reciente reforma tributaria, sancionada por el Congreso Nacional a través de la Ley 27.430 en materia de IVA amplía su objeto incorporando los servicios digitales prestados por un sujeto residente o domiciliado en el exterior en la medida que su utilización o explotación efectiva se lleve a cabo en el país.

La forma en la que hasta ese momento se venían desarrollando y estructurando estas operaciones cuando son prestadas por sujetos del exterior había llevado a que la inversión en el país se viera desalentada, en detrimento de la actividad de los sujetos prestadores domiciliados fronteras adentro. De esta manera, la ley pretendió poner en un plano de igualdad a los prestadores locales respecto del prestador residente o domiciliado en el exterior.

Mediante el Decreto 813/2018 se precisó la definición de los sujetos del exterior y, consecuentemente, la de los sujetos del país, de los responsables sustitutos por la tributación que nos ocupa y de los intermediarios que intervinieran en el pago de la operación.

También se precisó el momento para definir el monto de la tributación por los servicios digitales según la misma fuera cumplida por el prestatario o por el intermediario del caso, privilegiando la actuación de este último si existiera.

En particular, los intermediarios quedaron involucrados en un régimen de percepción del que resultan agentes, sostenido en listados de prestadores de servicios desde el exterior de nuestro país, confeccionados y actualizados por la Administración Federal de Ingresos Públicos.

\section{B. Ley de economía del conocimiento}

El 10 de junio de 2019, se publicó en el Boletín Oficial de la República Argentina la Ley 27.506 por medio de la cual se creó el Régimen de Promoción de la Economía del 
Conocimiento (RPEC), que determinaba para el periodo 2020-2029 una serie de beneficios fiscales para un conjunto de actividades económicas que conforman la Economía del Conocimiento (EdC).

Tal régimen implica, a grandes rasgos, la continuidad y ampliación del Régimen de Promoción de la Industria del Software (RPIS), creado por la Ley 25.922 y cuya vigencia caducó el 31 de diciembre de 2019. De hecho, la mencionada ley entró en vigor el $1^{\circ}$ de enero de 2020.

Principales características del régimen

\section{- Beneficiarios}

El RPEC contempla beneficios para empresas que desarrollen como actividad principal alguna de las siguientes actividades:

- Industria del software.

- Producción y posproducción audiovisual.

- Biotecnología, bioingeniería y aplicaciones.

- Servicios geológicos y de prospección, y servicios vinculados con la electrónica y las comunicaciones.

- Servicios profesionales, siempre que se destinen a la exportación.

- Nanotecnología y nanociencia.

- Industria aeroespacial y satelital.

- Producción de bienes y servicios relacionados con la automatización de procesos.

Además de ese requisito, las empresas deben satisfacer algunas condiciones adicionales en materia de gasto en investigación y desarrollo y comercio exterior, entre otras.

- Beneficios fiscales

El RPEC contempla los siguientes beneficios fiscales:

- Estabilidad fiscal a nivel nacional, y de las provincias y municipios que adhieran al régimen.

- Aplicación del 100\% del Mínimo no Imponible para las Contribuciones Patronales previstas en la Ley 27.430 .

- La emisión de un bono fiscal por 1,6 veces el monto pagado por concepto de contribuciones patronales, aplicable al pago de impuestos nacionales.

- La no aplicación de retenciones y percepciones del IVA.

- La aplicación de una alícuota reducida de $15 \%$ para el impuesto a las ganancias. 
Por otro lado, el RPEC contempla la creación de dos contribuciones para ser pagadas por parte de los beneficiarios del régimen:

- Hasta el $4 \%$ de los beneficios obtenidos, destinados al financiamiento de los procesos de control requeridos para verificar el cumplimiento de las exigencias de la norma.

- Hasta el 1,5\% de los beneficios obtenidos para financiar el Fondo Fiduciario para el Desarrollo del Capital Emprendedor.

- Requisitos para acceder al régimen

Cumplir con al menos dos de las siguientes condiciones:

- Acreditar la realización de mejoras continuas en la calidad de sus servicios, productos o procesos, o mediante una norma de calidad reconocida aplicable a sus servicios, productos o procesos.

- Acreditar indistinta o conjuntamente, la realización de erogaciones en actividades de: - Investigación y desarrollo en las actividades del artículo $2^{\circ}$ en un mínimo del $3 \%$ de su facturación total.

- Capacitación de los empleados afectados a las actividades del artículo $2^{\circ}$ en un mínimo del $8 \%$ de la masa salarial total.

- Acreditar la realización de exportaciones de bienes o servicios que surjan del desarrollo de alguna de las actividades promovidas de, al menos, un $13 \%$ de la facturación total correspondiente a esas actividades. Para el caso de los servicios profesionales, el mínimo de exportaciones es del 70\%. Para las micro y pequeñas empresas, el mínimo es del $45 \%$.

Asimismo, se considerará que se cumple con el requisito de actividad principal, cuando el porcentaje de facturación en las actividades promovidas represente al menos un $70 \%$ respecto del total de la facturación. Además, las empresas se deben inscribir en el registro del régimen.

De esta manera, las microempresas con antigüedad menor a los tres años solo deberán acreditar que realizan en el país, por cuenta propia y como actividad principal, alguna de las actividades comprendidas en el régimen. Las empresas que aún no tienen facturación se pueden inscribir con una declaración jurada y un modelo de negocio consistente con los requisitos.

\section{- Beneficios}

- Estabilidad fiscal: los beneficiarios no podrán ver incrementada la carga tributaria nacional total. Esta estabilidad se hará extensiva a las provincias, Ciudad Autónoma de Buenos Aires (CABA) y municipios en la medida en que adhieran a la ley. La presión tributaria se calcula al nivel de cada jurisdicción. 
- Contribuciones patronales: se aplica de manera inmediata el máximo del Mínimo No Imponible (MNI) previsto en la Ley 24.430, con lo que no resulta aplicaba el esquema progresivo. Además, los beneficiarios recibirán por única vez un bono de crédito fiscal transferible equivalente a 1,6 veces las contribuciones patronales. Ese bono se puede aplicar al pago del impuesto a las ganancias y el IVA. El bono fiscal no se tomará en cuenta al momento de calcular la ganancia neta imponible.

- IVA: los beneficiarios no serán sujetos pasibles de retenciones ni percepciones del IVA.

- Impuesto a las ganancias: los beneficiarios tributarán una alícuota reducida del $15 \%$ más la correspondiente alícuota aplicable en caso de distribución de dividendos, que a partir de 2020 será del 13\%. Asimismo, los beneficiarios podrán deducir un crédito por los gravámenes análogos efectivamente pagados o retenidos en el exterior, de conformidad con lo establecido por la ley de impuesto a las ganancias, cuando se trate de ganancias de fuente argentina. El referido cómputo procederá hasta el límite del incremento de la obligación tributaria originado por la incorporación de esas ganancias.

- Financiamiento de la investigación: se contempla la asignación de recursos al Fondo Fiduciario para el Desarrollo del Capital Emprendedor (FONDCE).

- Contribuciones de los beneficiarios

Los beneficiarios deberán hacer las siguientes contribuciones:

- Hasta 4\% del beneficio total obtenido para financiar las tareas de auditoría y control por parte del Ministerio de Producción y Trabajo.

- Hasta el 1,5\% del beneficio para el Fondo Fiduciario para el Desarrollo del Capital Emprendedor (FONDCE).

\section{Monedas digitales y criptomonedas. Su regulación en el impuesto a las ganancias. Régimen de información}

No fue sino hasta la llamada reforma tributaria (Ley 27.430) que se regularon legalmente las criptomonedas en la Ley del Impuesto a las Ganancias, o al menos esa habría sido la intención después de los resultados extraordinarios que escaparon a la esfera fiscal por no estar dentro de los hechos imponibles que pudieran determinar sus ganancias.

No obstante, y volviendo a la intención del legislador, su inclusión en la Ley del Impuesto a las Ganancias no fue fácil, en primer lugar, por su caracterización como monedas digitales (algunos autores señalan que ello se debió a la clasificación usada como monedas virtuales por la mayor parte de las legislaciones extranjeras y a la utilizada por la Unidad de Información Financiera [UIF] en nuestro país) que ya había mostrado interés en ese mercado y su evolución (al día de hoy, lo sigue haciendo).

Pues bien, esta clasificación no trajo pocos problemas al momento de determinar su gravabilidad ya que el término que finalmente se utilizara en el texto legal no identificaba 
plenamente a las criptomonedas o criptoactivos, dentro de los cuales se encuentran los bitcoin y los token, entre otros más.

Además, la dificultad es aún mayor, si se tiene en cuenta que no era una moneda emitida por un país como tampoco se podría clasificar dentro de una fuente, con lo cual las dificultades para liquidar la renta eran imaginables. Cabe destacar que varias de las rentas financieras gravadas (mediante el impuesto cedular) en el texto de la citada ley han sido dejadas sin efecto, como más adelante se explicará; no obstante, las obtenidas en el concepto analizado continúan vigentes sin modificaciones en cuanto a su gravabilidad.

En ese sentido, la liquidación del impuesto a las ganancias derivada de la venta de criptomonedas variará dependiendo de la fuente de la ganancia: si es argentina o extranjera.

Según la ley, serán de fuente argentina cuando el emisor de las criptomonedas se encuentre ubicado en el país. De lo contrario, serán de fuente extranjera y, en el caso del bitcoin, que no cuenta con un emisor centralizado, sino con mineros distribuidos por todo el mundo, se determinará que es de fuente argentina y la alícuota del impuesto será del $15 \%$ cuando se enajenen monedas digitales en pesos con cláusula de ajuste o en moneda extranjera, o del $5 \%$ cuando sea en pesos, así fuera aclarado a fines de diciembre de 2019 por la reglamentación de la ley. De todas formas, acá surge otro inconveniente: las monedas digitales no se emiten en dólares u otra divisa, sino que son valores en sí mismos: la falta de claridad legal complica la correcta liquidación del impuesto, como fuera expresado anteriormente.

Asimismo, la Resolución General 4614 estableció un régimen informativo mensual que deben cumplir las casas de cambio locales de criptomonedas entre otros entes, incluyendo bitcoin y las altcoins. Por consiguiente, desde noviembre de 2019, estos deberán informar desde el nombre del titular de la cuenta hasta los montos de los operadores y saldos finales.

En su momento, la AFIP explicó la necesidad de obtener información detallada, oportuna y precisa para regular las obligaciones de los comerciantes.

No cabe duda de que esta actividad económica sigue despertando interés en las autoridades gubernamentales y específicamente en las fiscales, y su comportamiento es aún materia de análisis. Se entiende que un excesivo rigor formal o imprecisiones en su regulación puede llegar a desalentar una actividad que puede actuar como alternativa de inversión en situaciones de crisis, como las que se están viviendo actualmente, pero también que la presencia prudente puede desalentar ciertas maniobras instrumentadas a través de las mencionadas criptomonedas.

\section{Medios electrónicos de pago en Argentina. Plataformas digitales. E-commerce}

En el país, las autoridades monetarias han asumido hace unos años (con continuidad de este gobierno) la política pública de ir incorporando tecnología a las operaciones comerciales de la población ampliando la oferta de posibilidades en primer lugar, de los medios 
más conocidos como las tarjetas de crédito y débito, sofisticándose con el tiempo en formas como la utilización de código QR o las llamadas billeteras virtuales, entre otras, para satisfacer los pagos.

La esperada masividad de su utilización resultaba -y resulta- inversamente proporcional a la utilización del dinero billete o cash, tan difundido en nuestras costumbres, por lo cual su imposición no requiere solamente de la decidida voluntad oficial, sino de educación cultural -en rigor una transformación cultural-, en el entendimiento de que la bancarización generalizada redunda en un beneficio para la comunidad al solidificar los ingresos públicos y con ello las posibilidades de ejecutar políticas públicas que permitan llegar a la mayor cantidad de personas posibles, en cantidad y en calidad.

No obstante, aun con grandes campañas en contra de su uso, el efectivo sigue siendo visiblemente cómodo para parte de la población en detrimento de medios vinculados a la tecnología electrónica y digital. No hay dudas de que esos casos no escapan a la lógica de lo que se entiende como una modalidad que, lejos de ser las más eficiente, resulta cómoda para quienes la utilizan.

Finalmente, existen otras medidas antes o prepandemia en la economía digital, entre ellas la facturación fiscal electrónica que empezó a fines de 2018, el Libro de Sueldos Digital a partir del año 2019 que se utiliza en la seguridad social para la declaración de los empleados y el IvA libro digital desde el año 2019.

\section{E. La economía digital frente a la emergencia originada en la pandemia covid-19}

Durante este tiempo que llevamos de pandemia en nuestro país, los cambios más significativos se reflejan en la Ley de Economía del Conocimiento y en los medios electrónicos de pago como seguidamente comentamos. En tanto, en el IVA -servicios digitales- y en el impuesto a las ganancias -impuesto cedular- no ha habido cambios como consecuencia de esta situación tan excepcional que hoy nos toca vivir.

En este sentido, y con relación a la Ley de Economía del Conocimiento, como mencionamos anteriormente, la misma tenía como fecha de entrada en vigor el primer día hábil de 2020. Sin embargo, el 15 de enero de 2020, mediante Resolución 30/2020 del Ministerio de Desarrollo Productivo, se decidió suspender su aplicación. El argumento fue que era necesario más tiempo para analizar y procesar las solicitudes de adhesión al Régimen de Promoción de la Economía del Conocimiento presentadas hasta el momento en que fuera dictada la normativa complementaria correspondiente.

Así las cosas, el Poder Ejecutivo Nacional Argentino envió, en febrero de 2020, al Congreso un nuevo Proyecto de Ley en reemplazo del anterior, con algunas modificaciones, pero manteniendo la mayoría de los artículos. Cabe señalar que el nuevo proyecto no deja de lado el objetivo primordial del régimen ya creado, y la finalidad de este; conforme explicó el ministro de Desarrollo Productivo, Matías Kulfas, resulta procedente realizar ciertas modificaciones con el fin de lograr una ley más progresiva, equitativa, federal y 
solidaria, que acompañe los propósitos de la Ley de Solidaridad Social y Reactivación Productiva.

El nuevo proyecto quedó sin tratar como consecuencia del covid-19 y el aislamiento social, preventivo y obligatorio que suspendió, entre muchas otras cosas, las sesiones ordinarias dentro del Parlamento nacional.

Ahora bien, es de destacar que durante la cuarentena se habilitó su tratamiento bajo la modalidad de sesión virtual del Congreso.

En plenario, las comisiones de Comunicaciones e Informática y de Presupuesto y Hacienda han considerado el nuevo Proyecto de Ley sobre Modificación del Régimen de Promoción de la Economía del Conocimiento dictaminando a favor de su sanción. El texto fue enviado al Senado, y se deberá esperar a que finalice el aislamiento social, preventivo y obligatorio para su sanción.

Se puede concluir que esta nueva Ley de Economía del Conocimiento fue impulsada durante la pandemia del covid-19, con el entendimiento de que impulsará una industria necesaria que será de importancia para afrontar las secuelas que se avecinan en la economía cuando se realice la apertura de la cuarentena.

La economía digital tuvo un crecimiento excepcional en los últimos años, y la industria vinculada con la innovación y la tecnología será seguramente una fuente de crecimiento del empleo, ayudará a relacionar transversalmente todos los sectores y, sobre todo, ayudará a transformar la economía de nuestro país a través del conocimiento.

Por otro lado, y vinculado a los medios electrónicos de pago, a partir de la llegada de la pandemia a muestras vidas y a nuestras costumbres, algunas cosas cambiaron ante el miedo al contagio del covid-19 y a las recomendaciones de la Organización Mundial de la Salud (oms) (entre otros, necesidad de no fomentar el contacto físico y en lo que a medios de pago electrónico se trata, el pago mediante contactless).

Así, comenzaron a fomentarse los medios electrónicos y digitales de pago como nunca había ocurrido con la utilización de diversas plataformas digitales ofrecidas, que funcionan como una solución a esta coyuntura y agilizan el E-commerce.

En el marco del trabajo, no aparece muy oportuno buscar razones que expliquen por qué ocurre una u otra cosa o abrir un debate -muy válido por cierto- sobre las ventajas de la trazabilidad de los pagos mediante medios electrónicos y la privacidad del dinero efectivo, y sí en cambio destacar que ante la llegada de una situación repentina que condicionó fuertemente nuestras costumbres como la manera en que son canceladas las obligaciones dinerarias, las plataformas digitales ofrecidas por los bancos y las fintech estaban a disposición, al igual que los medios electrónicos de pago (salvo honradas excepciones), alineando el ecosistema de la economía 4.0 a las necesidades de la sociedad.

Los medios de pago electrónicos existentes son:

- Tarjeta de débito: está vinculada a una cuenta bancaria. Una de sus principales características es que, al momento de pagar, el monto se reduce automáticamente del saldo disponible en la cuenta relacionada. Además, permite realizar otras operaciones 
a través de cajeros electrónicos, como consultar saldos, hacer transferencias, extraer efectivo, realizar pago de servicios, cargar saldo de la tarjeta SUBE. Todos los comercios, empresas, profesionales, monotributistas deben aceptar el pago con tarjeta de débito, solo están exentos los locales cuya actividad se realice en localidades con menos de mil habitantes o cuando las operaciones no superen el valor de los $\$ 10$, según lo reguló la Ley 27.253 del 8 de junio de 2016, y su reglamentación. El pago con débito automático no debe tener un monto adicional o recargo.

- Billetera electrónica: transferencias de desde un teléfono celular a otro a través de aplicaciones para teléfonos móviles.

- POS móvil: transferencias iniciadas por medio del deslizamiento de una tarjeta por un dispositivo lector que se conecta al celular o a una tableta.

- Botón de pago: sirve para realizar pagos en línea e insertar en la propia web, los cuales se acreditan inmediatamente en la cuenta del receptor y permiten comprar, pagar, enviar y recibir dinero de manera fácil, práctica y segura. El Banco Central busca que este mecanismo represente una opción atractiva para los pequeños comercios y proveedores de servicios, que mejore su disposición a recibir medios de pago electrónico, y, de esa manera contribuya a ampliar la red de aceptación de estos pagos, destaca en su web.

- Débito inmediato (Debin): habilita a las entidades financieras y a nuevos actores de la industria de medios de pago a debitar fondos de las cuentas bancarias de sus clientes, previa autorización de estos, para cursar pagos con una transferencia directa y también solicitarla desde la computadora personal o el celular.

- Tarjeta de crédito: es un instrumento de pago gestionado por una entidad financiera o una empresa emisora. Una de las características de este medio de pago es que ofrece la posibilidad de hacerlo en cuotas, muchas veces sin recargo de intereses.

Dentro de las ventajas se pueden enumerar:

- Optimización de tiempo.

- Disminución en costos financieros.

- Comodidad, agilidad y facilidad en movimientos transaccionales.

- Evita el contacto directo con personas (pensando en la pandemia covid-19).

- No requiere de punto de venta o instalaciones físicas para funcionar.

En virtud de lo expuesto resta analizar en una siguiente etapa si esta modalidad de pago llegó para quedarse entre nuestras costumbres en la denominada nueva normalidad o no; no obstante, aparece como dato alentador que a partir de ahora el alcance a la mayor parte de la población sea posible. La difusión del acceso a internet por canales móviles, con más de 32 millones, según los últimos datos del Indec; casi 9 millones de cuentas para pago de remuneraciones por parte de unos 230 mil empleadores, más la acreditación de haberes en cuenta bancaria a la mayor parte de los casi 7 millones de jubilados, 1,5 millones de 
pensiones no contributivas y casi 4 millones de perceptores de la asignación universal por hijo (AUH), y la entrega de la Tarjeta Alimentaria, posibilitaría la aceptación por parte del conjunto de la sociedad del uso del dinero electrónico.

A mayor abundamiento, es menester agregar que el Estado nacional viene adoptando en esta línea de digitalización de los procesos, diversas medidas (algunas pocas han sido dejadas sin efecto en el último tiempo) que siguieron la tendencia de reconocer una mayor digitalización de la economía.

Algunas de las medidas que podemos destacar son las siguientes:

- Se implementó la Plataforma de Trámites a Distancia (TAD) como medio de interacción con la administración pública, a través de la recepción y remisión por medios electrónicos de presentaciones, solicitudes y comunicaciones. En dicho marco, se intenta, además, generar equivalencias ágiles a la emisión de poderes, firmas certificadas, etcétera.

- Se eliminó el artículo $4^{\circ}$ de la Ley 25.506 (2) de Firma Digital, que establecía limitaciones al uso de la firma digital, y se creó la llamada Plataforma de Firma Digital Remota, para promover el acceso de los ciudadanos a certificados digitales para firmar digitalmente.

- Se implementó una herramienta de identificación biométrica que permite a las empresas acceder al Registro Nacional de las Personas (RENAPER), para así validar la información personal que pudieran recolectar de sus clientes en el proceso de on-boarding digital.

- Se autorizó la apertura de cuentas bancarias de manera no presencial, y se flexibilizó la forma en que se permite a los bancos instrumentar, conservar y reproducir documentos. A partir de ello, los bancos tradicionales pudieron mejorar sus plataformas de home banking (incluyendo, entre otras cosas, on-boarding digital) y comenzaron a surgir bancos $100 \%$ digitales.

- Se habilitó el depósito electrónico de cheques emitidos en papel, y luego se habilitó también la posibilidad de emitirlos, avalarlos y endosarlos directamente de manera digital, no solo con firma digital, sino también con firma electrónica avanzada. También se modificó el régimen de la letra de cambio y pagaré en este último sentido.

- Se dictaron distintas medidas que facilitan la realización de pagos electrónicos, como los llamados pagos electrónicos inmediatos (PEI), el débito inmediato (DEBIN) -este último ahora con algunas limitaciones en cuanto a su uso- y el alias de Clave Bancaria Uniforme (CBU).

- Se reguló el código QR, que ha sido utilizado especialmente por las billeteras digitales y permite pagos presenciales rápidos (y a cierta distancia, sin tener que intercambiar manualmente billetes o tarjetas).

- Se modificó el régimen de la tarjeta de crédito para permitir la suscripción de los contratos de emisión a distancia, con firmas electrónicas avanzadas. 
- Se permitió constituir sociedades por acciones simplificadas (sas) de manera remota y con firma digital, así como que los libros pudieran llevarse de la misma manera (régimen bajo revisión por la actual conducción de la Inspección General de Justicia). Es de esperar que durante este año se viabilice el otorgamiento de poderes digitales en los términos de la Ley 27.349 (3) de Apoyo al Capital Emprendedor.

- El Poder Judicial adoptó (en algunas jurisdicciones más que en otras) distintas herramientas y sistemas a los efectos de poder tramitar los procesos judiciales -al menos parcialmente- de manera digital (AFIP está en pleno proceso de implementación).

Siguiendo con el análisis, la llegada de la pandemia originó en nuestro país la adopción de medidas acordes a la situación de emergencia en el intento de asistir rápidamente a la población en general y a los mas necesitados en particular. En la mayoría de los casos tuvimos que quedarnos en nuestras casas adaptando las distintas actividades para sostener nuestras economías y así la sociedad en su conjunto. En este punto es importante detenerse a observar que los grandes ganadores de esta coyuntura fueron las plataformas digitales utilizadas en forma remota, ya sea para garantizar la continuidad de la actividad laboral en sus diversas modalidades (teletrabajo, home office) o simplemente para proveerse de alimentos, entre otras muchas más actividades desde lúdicas hasta videoconferencias o servicios médicos; en todos esos casos se recurrió a las herramientas que provienen de la economía digital para continuar.

Por su parte, hemos visto en este trabajo que dentro de las decisiones adoptadas por el Estado nacional ha habido avances consistentes como la adaptación de la Mesa de Entradas del Ministerio de Economía de la Nación en la tramitación digital, así como también observamos la flexibilización de avances muy importantes como el reconocimiento biométrico en los trámites para su agilización.

En este sentido, resulta imperioso que el Estado retome de manera inmediata el impulso en la implementación, la ampliación y la promoción de medidas como las antes citadas, así como que analice, diseñe y despliegue, junto al sector privado, nuevas propuestas y herramientas que posibiliten el desarrollo de nuestra sociedad y economía en un entorno digital y de innovación permanente. Pero no solo es el Estado quien debe entender esta cuestión como una prioridad, sino también las empresas y asociaciones de profesionales (incluso aquellas que se sienten amenazadas por esta tecnología). Todos ellos deben adoptar estas herramientas y repensar la manera en que operan y prestan sus servicios en la actualidad. Hoy más que nunca, todos y cada uno de nosotros debemos proponer, discutir y avanzar con estos temas. Esto tiene que hacerse de una manera creativa, flexible, racional, pero también clara y profesional, trabajando con el marco normativo existente, identificando los institutos y conceptos jurídicos que aplican en cada caso y detectando cuáles son sus capacidades y limitaciones (Mora, 2020). 
Finalmente, y reafirmando el camino digital como herramienta permanente de la nueva normalidad pospandemia, destacamos que desde el día de la fecha B.O.01.06:2020 rige el Padrón Federal de Impuestos confeccionado con tecnología Blockchain.

\section{F. Tributación en la economía digital. Servicios digitales prestados desde el exterior. Conceptos y medidas adoptadas por las provincias. Impuesto sobre los ingresos brutos}

Tal como sucedió con la Revolución Industrial, la evolución de la tecnología en materia de comunicación a distancia, transmisión de datos y conectividad ha producido un cambio muy fuerte en la economía y en la forma de interconexión entre la oferta y la demanda.

Como todo cambio, implica una revisión de estructuras y fundamentos que se daban como válidos y plenamente aceptados. La llamada economía digital es hoy una parte de crecimiento exponencial dentro de la economía tradicional y, probablemente, llegue a ser en breve, la economía.

La fiscalidad y la tributación no solo no están ajenas a este fenómeno, sino que se ven obligadas a repensar conceptos. Desde hace un tiempo, de manera agrupada y también unilateralmente, la mayoría de los países han empezado a estudiar acciones con respecto a la forma y a las condiciones en las que las empresas proveedoras de servicios y soluciones digitales deben tributar. El principal problema en este sentido es la territorialidad jurisdiccional para determinar qué fisco tiene potestad sobre ese tributo.

Podemos esbozar una rápida clasificación de servicios digitales prestados por empresas que participan en el campo de la economía digital:

- Redes de colaboración (Airbnb, Booking, Trip advisor, Mercado libre, Amazon, etc.).

- Entretenimiento y cultura (Netflix, Spotify, etc.).

- Soluciones on-line (Saas-Service as a Software).

Cada operatoria realizada a través de estas plataformas representa una forma particular de acto económico susceptible de tributación.

La economía digital trae aparejada la necesidad de repensar el concepto tradicional sobre tributación en los impuestos directos, en especial en el impuesto a las ganancias de las sociedades (sujetos residentes tributan sobre sus ganancias globales, sujetos no residentes sobre sus ganancias en establecimientos permanentes). La problemática que trae aparejada la economía digital reside básicamente en la concepción de la territorialidad en la creación e identidad de valor, economías de escala sin presencia física, activos intangibles como núcleo del negocio y la participación de usuario en la generación de valor.

La OCDE, en el marco de sus acciones para combatir la erosión de la base imponible y el traslado de beneficios (BEPS por sus siglas en inglés) ha emitido directrices, informes y recomendaciones con medidas de acción para adoptar por parte de los países miembros, orientadas a dar solución a la tributación en el campo de la economía digital. Dada la 
complejidad del tema, la constante lucha de intereses (la mayoría de las grandes empresas que operan en este mercado son originarias de los países miembros de la OCDE) y el temor de muchos países a que la carga impositiva desaliente la radicación, inversión y generación de empleo, han ido posponiendo una solución real y definitiva.

En 2014, la oCDE emitió un informe provisional en el que esbozaba un listado de manifestaciones de actividades de economía digital y dudas sobre la territorialidad de la tributación y los paradigmas tradicionales de residencia y fuente. En 2015 plantea caminos alternativos para explorar, entre los que se destaca el concepto de presencia digital significativa.

En 2018, aclara que la proliferación de enfoques unilaterales puede tener efectos adversos. La comunidad europea también empezó a explorar soluciones, teniendo en vista dos soluciones, una de corto plazo (comúnmente llamada tasa de google, se aplicaría una tasa del $3 \%$ sobre las utilidades a empresa con una facturación anual superior a 750 millones de euros) y una solución de más largo plazo vinculada al concepto de presencia digital significativa, uno de los caminos propuestos por la OCDE. Se esperan nuevos informes de la OCDE, hoy no se ha adoptado ninguna solución definitiva.

En junio de 2018, la Corte Suprema de Estados Unidos, en relación con el impuesto a las ventas minoristas, falló dándole la razón al estado de Dakota del Sur en su reclamo por el pago del impuesto contra la empresa Wayfair Inc., en un caso de ventas a través de plataformas digitales sin establecimiento o presencia física dentro del estado. El fallo argumenta que las nuevas formas de operación basadas en la tecnología no implican que no haya presencia por parte de la empresa, sino que, por el contrario, hay una presencia digital.

El impuesto a los ingresos brutos apoya la razón de su existencia en tres supuestos: actividad habitual, onerosa y desarrollada dentro del territorio de la jurisdicción. Este último es justamente el aspecto más conflictivo para la aplicación del impuesto. Para que pueda gravarse una actividad con el impuesto a los ingresos brutos, esta debe llevarse a cabo en todo o en parte dentro de los límites territoriales de la jurisdicción.

Los que argumentan en contra de la aplicación del impuesto a los ingresos brutos sobre este tipo de servicios digitales prestados desde el exterior entienden que no se cumple con el supuesto de territorialidad porque la actividad es prestada desde el exterior, sin nexo territorial o presencia física.

Por el contrario, los que argumentan a favor de la aplicación del impuesto, manifiestan que parte de la actividad se presta dentro de la jurisdicción. Las nuevas formas de conectividad y la evolución tecnológica hacen que sea indispensable para la prestación del servicio que parte de la actividad se desarrolle localmente. A modo de ejemplo, se mencionan breve y sucintamente ejemplos como contratos con redes de distribución de contenidos, facilitadoras de mercados en línea, procesamiento de cobro, gestión de pedido, delivery, aplicaciones, datos auxiliares (cookies), etc.

La CABA fue pionera en emitir normativa con el fin de gravar con el impuesto a los ingresos brutos a los servicios digitales prestados por empresas radicadas en el exterior. La aplicación de la resolución general se suspendió por manifestar las operadoras de tarjetas 
de crédito la imposibilidad técnica de actuar como agentes de retención para estos casos en particular, pero además, y al ser un tema tan nuevo en ese momento y sin demasiada opinión doctrinaria, no quedaba claro en la normativa cuál sería el sustento territorial.

Posteriormente, Córdoba intentó avanzar sobre el tema, a través de la ampliación en la definición del hecho imponible, manifestando que hay actividad gravada dentro de la provincia siempre que se produzcan efectos económicos (consumo, inversión, etc.) sobre bienes, sociedades o personas dentro de la misma. No lo expresa como un impuesto al consumo, sino que, para el caso de servicios prestados desde el exterior, toma al consumo como un indicio de actividad dentro de la provincia. La Asociación de Bancos de la Argentina judicializó el tema, manifestando que no corresponde a los bancos actuar como agentes de percepción/retención en este tipo de operaciones dado que considera que no se cumple la condición de territorialidad en la aplicación del impuesto y que Córdoba excede sus atribuciones jurisdiccionales delegadas por la Constitución Nacional.

Otras provincias como Tucumán, Salta, y Santa Fé avanzaron en forma similar a Córdoba, ampliando la definición de hecho imponible y haciendo hincapié en los efectos económicos producidos por este tipo de servicios.

La Provincia de Buenos Aires abordó el tema en concordancia con supuestos aceptados internacionalmente, utilizando uno de los criterios recomendados por la OCDE: presencia digital significativa (posteriormente, Córdoba también sumó este concepto a su definición de hecho imponible). Hay presencia digital significativa siempre que se superen parámetros de cantidad de usuarios, montos anuales de ingresos y cantidad de contratos celebrados. Utiliza la figura del responsable sustituto, designando en representación de la empresa prestataria del exterior al usuario del servicio y establece que las tarjetas de crédito a cargo del cobro del servicio actuarán como agentes de liquidación e ingreso, aplicando una alícuota del $2 \%$. A través de la Resolución de Arba 39/2019, en conjunto con AFIP 4632, quedó habilitado el cobro, aunque por temas de operatividad, y ante la situación de pandemia por el covid-19, la nueva gestión de Arba decidió prorrogar la entrada en vigencia del régimen.

Con la sanción de la Ley 6279, la CABA incorporó a su código fiscal un esquema similar al de la Provincia de Buenos Aires, aunque enuncia en la definición del hecho imponible los efectos económicos y la presencia digital dentro de su territorio. La resolución conjunta AGIP/AFIP 4649 instruye para actuar a los operadores de tarjeta a partir del $1^{\circ}$ de marzo de 2020, utilizando también la figura del responsable sustituto. Al igual que en el caso de la Provincia de Buenos Aires, y a raíz de pandemia de covid-19, la Ciudad de Buenos Aires postergó la puesta en marcha del régimen establecido en principio al $1^{\circ}$ de agosto de 2020 .

A contramano de esta decisión, y como consecuencia de los desequilibrios fiscales que provocan la fuerte caída en la recaudación, consecuencia de la pandemia, La Pampa optó por avanzar con la gravabilidad de los servicios digitales prestados desde el exterior, y está trabajando en la reglamentación de lo que ya había establecido en su código fiscal hace un par de años, bajo el criterio de efectos económicos sobre bienes o personas. 
Un tema de debate el mundo, sobre el que los fiscos se ven obligados a avanzar de forma firme pero prudente en virtud de las nuevas formas de economía derivadas de la evolución tecnológica y social.

\section{Panorama fintech: medios de pago digitales y comercio electrónico. Estado de situación pre y pospandemia}

El aislamiento social preventivo y obligatorio obligó rápidamente a un cambio de hábitos provocando la aceleración del proceso de la digitalización de la economía. El e-commerce registró durante el año 2019 un crecimiento, según cifras oficiales del estudio anual de la Cámara de Comercio Electrónico en Argentina, del $76 \%$ alcanzando una facturación del \$403.278 millones de pesos. La pandemia potenció este comportamiento obligando a las empresas a la adopción y desarrollo de canales digitales. Tan solo en la categoría supermercado el crecimiento durante las primeras tres semanas de la cuarentena alcanzó un $300 \%$ con respecto a la situación prepandemia, y el rubro farmacia un aumento del $60 \%$; estos fueron los rubros más demandados y, dado a que ya venían operando con esa modalidad, solo debieron incrementar y aceitar el proceso de distribución para acelerar los tiempos de entrega.

Muy diferente es la experiencia de muchas MiPYME que en su mayoría no estaban preparadas en infraestructura para un acontecimiento de semejante envergadura y debieron capacitarse o reinventar el negocio ante la imposibilidad de utilizar los canales habituales.

Según un informe sobre el estado de la digitalización en América Latina, de la Corporación Andina de Fomento (CAF) -banco de desarrollo constituido y conformado por 19 países de América Latina y el Caribe, España y Portugal, y 13 bancos privados de la región-, Argentina está segunda en el ranking de operaciones de comercio electrónico, con un uso de $6,73 \%$, después de Panamá, que alcanza al 8,03\%, ambos por encima del promedio regional de 5,7\% y por debajo del $11,52 \%$ de los países de la OCDE.

Es importante tener en cuenta, dada la situación, el grado de accesibilidad y penetración de internet a nivel país. La Argentina se ubica por encima del promedio regional en cuanto a penetración de internet al alcanzar $85,84 \%$ contra una media latina de 78,78\%, aunque por debajo del $88,33 \%$ entre los países de la oCDE. El dato es positivo, aún cuando también se debe admitir que este nivel de penetración no es parejo en todo el territorio nacional, y que los mejores valores se alcanzan en las urbes más importantes. A este cambio de hábitos en el consumo se suma el cambio de hábitos en la modalidad de pago a través de plataformas digitales que, en sintonía con la situación, también creció fuertemente.

Las empresas y plataformas de tecnología financiera han visto gran parte de sus oportunidades de crecimiento en el rezago de innovación tecnológica y de políticas por parte de las entidades bancarias, habida cuenta de que ofrecen nuevas posibilidades a las personas que no necesitan manejar cuentas complicadas. Tiene además un alcance e interés geográfico más amplio. 


\section{A. Situación fintech prepandemia}

El número de empresas del sector creció un $110 \%$ entre julio de 2018 y julio de 2019. De esta manera ya son 225 las firmas que operan y que se reparten la torta de un mercado cada vez más competitivo, en el que la innovación es fundamental para sacar distancia al resto del pelotón.

La composición y distribución de las unidades de negocios se componen de la siguiente forma:

- 60 crédito fácil (asimilable a la actividad de préstamos).

- 39 pagos digitales.

- 29 proveedoras de tecnología (asimilable a los desarrollos informáticos).

- 25 monedas virtuales (asimilable a la compra y venta de divisas).

- 21 servicios B2B (asimilable a los desarrollos informáticos).

- 18 inversiones (asimilable a los agentes de bolsa).

- 16 crowfunding (asimilable a los fondos y sociedades de inversión.

- 13 insurtech (asimilable a los seguros).

- 4 ciberseguridad.

Entre los principales jugadores del sector financiero encontramos a Mercado Pagos, Ualá, Moni, Iúnigo, Wilowbank, Quiena, Colppy y Ripio, entre otros. El resto de estos puede categorizarse como pyme: el $80 \%$ cuenta con menos de 50 empleados y sus índices de facturación coinciden con los de este tipo.

El público no bancarizado (se estima que alcanza el $52 \%$ de la población adulta de nuestro país), y que, por no tener historial crediticio, no podían acceder a herramientas financieras tradicionales, comienza a ser captado por las fintech.

El crecimiento de la industria también se puede palpar en la emisión de tarjetas prepagas. Este segmento fue acaparado por Wilobank, Brubank y Rebanking -habilitados por el BCRA para operar como bancos digitales-, junto con Ualá y Mercado Pago.

Las operaciones de compraventa de divisas fue otro de los puntos salientes de las billeteras virtuales habida cuenta de que la adquisición por celular y home banking concentran entre el 80 y el $90 \%$ de las transacciones en moneda extranjera.

\section{B. Sector fintech durante el covid-19}

Como consecuencia del aislamiento social preventivo y obligatorio sufrido por la población, muchas de las gestiones bancarias que se realizaban quedaron repentinamente paralizadas. Esta situación significó un envión para un sector que se encuentra en las gateras a la espera de una posibilidad como es el sector de las fintechs. 
Como caso testigo tomaremos a la herramienta de mayor renombre, Mercado Pago, la que ha gozado de un fuerte crecimiento en su uso, mayoritariamente sustentado en el pago de servicios.

- $\uparrow 94 \%$ entre marzo y abril 2020 en nuevos usuarios únicos con respecto a situación prepandemia.

- $\uparrow 100 \%$ entre marzo y abril 2020 en pago de facturas con respecto a situación prepandemia.

- 4,7 veces más nuevos usuarios cuya primera transacción fue el pago de un servicio, mayoritariamente atado al pago de impuestos provinciales a través de dicha plataforma.

Los principales servicios que presentaron incrementos en los cobros a través de esta plataforma fueron:

- DIRECTV: $258 \%$.

- Personal Telf.: $164 \%$.

- Camuzzi Gas: $154 \%$.

- Movistar: $148 \%$.

- Cablevisión: $145 \%$.

- Claro: $113 \%$.

Asimismo, se adoptó la medida de no cobrar intereses por el atraso en el pago, y creó en su aplicación la Función Amigos que permite transferir dinero o hacer colectas para cubrir determinados gastos de otros usuarios.

Por su parte, Ualá también reflejó aumentos considerables, alcanzando:

- $\uparrow 60 \%$ transferencias realizadas a cuentas en Ualá.

- $\uparrow 300 \%$ pagos de servicios realizados desde la App.

- $\uparrow 40 \%$ de dinero depositado en Fondos Comunes de Inversión manejados desde Ualá.

Un escenario de gran oportunidad se plasmó con la aparición del ingreso familiar de emergencia (IFE). Dicha medida debía impactar en trabajadores informales y monotributistas que en muchos casos no estaban bancarizados. Ante esto, la Cámara de Fintech acercó un proyecto al Gobierno demostrando las bondades de sus soluciones. Sin embargo, cuando todo parecía encaminado, el gobierno optó por el sistema tradicional (8 millones de personas percibirán este subsidio, al menos $50 \%$ de las cuales no está bancarizada).

La Provincia de Buenos Aires, a través de su institución bancaria oficial (BAPRO) aprovechó esta oportunidad de captación relanzando su cuenta DNI (ya había sido lanzada a mediados de 2019), que superó el medio millón de aperturas de cuentas digitales, el $51 \%$ de las cuales fueron gestionadas por nuevos clientes del Banco. 
Asimismo, un grupo de entidades (las más grandes y que operan con red Banelco) está avanzando en su propia plataforma de pagos: BBvA, Macro, Santander y Galicia (propietaria de la fintech Naranja $\mathrm{X}$ ), entre más de una veintena de firmas, planean un desarrollo conjunto cuya principal ventaja será la interoperabilidad. Es decir, que los usuarios paguen con el mismo código QR en cualquier comercio adherido, sin importar de qué entidad financiera sean clientes.

Finalmente, resulta indispensable mencionar dos comunicaciones (prepandemia) del Banco Central de la República Argentina (BCRA) en la materia de análisis:

- Comunicación 6859 del 9-1-2020

Disponer que los fondos de los clientes acreditados en cuentas de pago ofrecidas por proveedores de servicios de pago (PSP) deberán encontrarse, en todo momento, disponibles -con carácter inmediato ante su requerimiento por parte del cliente- por un monto al menos equivalente al que fue acreditado en la cuenta de pago. A tal efecto, los sistemas implementados por el PSP deberán poder identificar e individualizar los fondos de cada cliente. Se consideran PSP a las personas jurídicas que, sin ser entidades financieras, cumplan al menos una función dentro de un esquema de pago minorista, en el marco global del sistema de pagos, tal como ofrecer cuentas de pago-cuentas de libre disponibilidad ofrecidas por un PSP a sus clientes para ordenar o recibir pagos-. El $100 \%$ de los fondos de los clientes deberá encontrarse depositado -en todo momentoen cuentas a la vista en pesos en entidades financieras del país. Sin perjuicio de ello, ante solicitud expresa del cliente, los saldos acreditados en cuentas de pago podrán ser transferidos para su aplicación a la realización de operaciones con fondos comunes de dinero en el país, debiéndose debitar la cuenta de pago. En este último caso, se requerirá que los saldos invertidos sean informados de manera separada del resto. Para la realización de transacciones por cuenta propia (pago de proveedores, pago de sueldos, etc.), los PSP deberán utilizar una cuenta a la vista operativa (de libre disponibilidad) distinta a la cuenta donde se encuentren depositados los fondos de los clientes.

Los PSP y los miembros de sus órganos de gobierno, administración y fiscalización, por los incumplimientos que se constaten respecto de las disposiciones previstas en esta comunicación, serán pasibles de la aplicación de las sanciones conforme a lo previsto en los artículos 41 y 42 de la Ley de Entidades Financieras y disposiciones concordantes.

- Comunicación 6885 30-1-2020

Establecer que los proveedores de servicios de pago que ofrecen cuentas de pago deberán cumplimentar la solicitud de inscripción en el Registro de Proveedores de Servicios de Pago que ofrecen cuentas de pago de la Superintendencia de Entidades 
Financieras y Cambiarias (SEFyC), dentro de los 30 días corridos posteriores al 1 de marzo de 2020, fecha en la que se habilitará este registro.

\section{Conclusiones}

A partir del análisis de las distintas medidas adoptadas por las diferentes reparticiones, centralizadas y descentralizadas, en las esferas nacional, provincial y municipal, así como también medidas que contribuyen al avance de la relación fisco-contribuyente y que son de suma importancia, teniendo en cuenta el sinnúmero de problemas que afectan y afectarán de manera abrupta y sin precedentes las relaciones económicas, políticas y sociales de nuestro país, podemos concluir que:

- Los países, sus gobiernos y específicamente las administraciones tributarias vienen padeciendo los efectos de la pandemia desde hace ya varias semanas sin vislumbrarse hasta el momento un horizonte de salida, razón por la cual la agenda de la gestión del Estado (en sus diversos niveles) ha estado claramente trazada por sus medidas. En este trabajo se ha intentado leer las mismas al fin de definir su alcance en el ámbito tributario, y se ha llegado a conclusiones propias en cada uno de los temas abordados.

- Las medidas adoptadas por las administraciones tributarias, en línea con otras de carácter no tributario, procuraron mayormente aliviar el peso de los tributos que recae sobre sus contribuyentes a través de la postergación de fechas de vencimientos impositivos, suspensión de juicios y ejecuciones fiscales, otorgamiento de planes de pago incluso a planes caducos, reducción de intereses de financiación y contribuciones de la seguridad social, suspensión del ingreso de las retenciones sobre los derechos de exportación, flexibilización de controles en los trámites con el fin de su agilización, suspensión de recategorizaciones y otras más, con la particularidad de que el foco se posó sobre los sectores más acuciados por la emergencia para, posteriormente, hacerlo sobre el resto de los contribuyentes y responsables.

- No cabe duda, entonces, de que la Administración Tributaria federal ha respondido a la coyuntura planteada con una posición clara sobre a qué sector de la sociedad le interesaba destinar el sacrificio fiscal en la recaudación de tributos, al menos en su mayor parte.

- Una vez superada la pandemia, en un contexto de nueva normalidad, procuramos que estas medidas paliativas dejarán de ejecutarse y quizás sea el momento de plantearse un esquema impositivo planificado integralmente junto a las provincias y los municipios, con mayor equidad. 


\section{Referencias}

H. Cámara de diputados de la Nación (2020). Proyecto de Ley: Regulación y promoción del teletrabajo. https://www4.hcdn.gob.ar/dependencias/dsecretaria/Periodo2020/ PDF2020/TP2020/2350-D-2020.pdf

Mora, S. (2020). La digitalización, los negocios fintech y la pandemia de covid-19. La Ley.

Oficina de Presupuesto del Congreso de la Nación (2020). Impacto financiero del covid-19 al 18/5/2020. Congreso de la Nación.

\section{Jurisprudencia}

Decreto 330/2020.

Decreto 300/AFIP/2020 (B.O. 20/03/2020).

Decreto 333/2020 (B.O. $\mathrm{N}^{\circ} 02 / 04 / 2020$ ).

Decreto 252/2020 (B.O.C.B.A. 22.04.2020).

Decreto 271/2020 (B.O. 07/05/2020).

Disposición de Presidencia 4/2020 (B.O. 15/04/2020), ratificada por Resolución 5/2020 (C.A.) (B.O. 20/04/2020).

Ley 10.691, Decreto 279/2020 30.4.2020 y Decreto 301/2020 B.O.Cba (29/4/2020).

Ley Provincial 13976, Decreto 368/2020 B.O. E. S. F. Resolución 006/2020 (API), Resolución 11/2020 (API), Resolución 0026/2020 (API) y Resolución 0029/2020 (API).

Ley 27541 Solidaridad Social y Reactivación Productiva y Emergencia Económica, Administrativa Tributaria y Fiscal (B.O. 23/12/2019). Decretos Reglamentario 316/2020 y RG 4690/AFIP/2020.

Ley 6301 (B.O.C.B.A. 12/05/2020). Emergencia Económica y Financiera del Ciudad. Decreto Reglamentario 210/2020 (B.O. C.B.A. 15/5/2020).

RG 4686/AFIP/2020 (B.O. 20/03/2020). 
RG 4704/AFIP/2020 (B.O. 28/04/2020).

RG 4687/AFIP/2020 (B.O. 20/03/2020).

RG 4704/AFIP/2020 (B.O. 18/04/2020).

RG 4701/AFIP/2020 (B.O 18/04/2020).

RG 4691/AFIP/2020 (B.O. 02/04/2020).

RG 4684/AFIP/2020 (B.O. 20/03/2020).

RG 4705/AFIP/2020 (B.O. 29/04/2020).

RG 4714/AFIP/2020 (B.O. 13/05/2020).

RG 4721/AFIP/2020 (B.O. 21/05/2020).

RG No 4725/AFIP/2020 (B.O. 28/05/2020).

RG 4718/AFIP/2020 (B.O. 15/05/2020).

RG 4721/AFIP//2020 (B.O. 21/05/2020).

RG 4700/AFIP/2020 (B.O. 17/04/2020).

RG 4689/AFIP/2020 (B.O. 31/03/2020).

RG 4696/AFIP/2020 (B.O. 15/04/2020).

RG 4694/AFIP/2020 (B.O. 09/4/2020).

RG 4685/AFIP/2020 (B.O. 20/03/2020).

RG 4699/AFIP/2020 (B.O. 17/04/2020).

RG 4688/AFIP/2020 (B.O. 30/03/2020).

RG 4701/AFIP 2020 (B.O. 17/04/2020).

Resolución 165/AGIP/2020 (B.O.C.B.A. 13/04/2020). 
Resolución 163/AGIP/2020 (B.O.C.B.A. 08/04/2020)

Resolución 164/AGIP/2020 (B.O.C.B.A. 13/04/2020).

Resolución 173/2020 (B.O 17.04/2020).

Resolución 178/AGIP/2020.

Resolución 188/AGIP/2020.

Resolución 192/AGIP/2020.

Resolución 183/AGIP/2020.

Resolución 194/AGIP/2020.

Resolución Normativa 16/2020 (ARBA) (B.O.P.BA 01/04/2020).

Resolución Normativa 17/2020 (ARBA) (B.O.P.B.A 06/04/2020).

Resolución Normativa 26/2020 (ARBA) (B.O.P.B.A.14/04/2020).

Resolución Normativa 27/2020 (ARBA) (B.O.P.B.A 12/05/2020).

Resolución Normativa 19/2020 (ARBA) (B.O.P.B.A 08/04/2020).

Resolución Normativa 24/2020 (ARBA) (B.O.P.B.A 14/04/2020).

Resolución Normativa 18/2020 (ARBA) (B.O.P.B.A 14/04/2020).

Resolución Normativa 23/2020 (ARBA) (B.O.P.B.A 14/04/2020).

Resolución 16/2020 (A.T.M.) (B.O. 01/04/2020).

Resolución17/2020 (A.T.M.) (B.O. 02/04/2020).

Resolución 24/2020 (A.T.M.) (B.O.M 24/04/2020).

Resolución 27/2020 (ATM) (B.O.M 05/05/2020).

Resolución 6/2020 (M.F.) (B.O.C.B.A. 12/05/2020). 
Resolución 2178/AGIP/2020 (B.O.C.B.A. 16.04.2020).

Resolución Plenaria 15/2020 (B.O 05/05/2020).

Resolución 6/2020 (M.F.) (B.O.Cba 12/05/2020).

Resolución Plenaria 15/2020 (B.O. 05/05/2020).

Fecha de recepción: 24 de junio de 2020

Fecha de aprobación par 1:01 de septiembre de 2020

Fecha de aprobación par 2: 16 de julio de 2020 